\title{
ANALISIS DIKSI DAN GAYA BAHASA DALAM NOVEL LONDON LOVE STORY KARYA
}

\section{TISA TS}

\author{
Suyani $^{1}{ }^{,}$Ratuwardarita $^{2}$, Arifardiansyah $^{3}$ \\ 11umbsuyani@gmail.com, ${ }_{2}^{2}$ ratuwardarita@yahoo.com, ${ }^{3}$ arifacong@gmail.com \\ Mahasiswa Pascasarjana Universitas PGRI Palembang
}

\begin{abstract}
Abstrak - Pengertian diksi atau pilihan kata menurut Keraf (2016:24) adalah pilihan kata atau diksi mencakup pengertian kata-kata mana yang dipakai untuk menyampaikan suatu gagasan, bagaimana membentuk pengelompokan kata-kata yang tepat atau menggunakan ungkapan-ungkapan yang tepat, dan gaya mana yang paling baik digunakan dalam suatu situasi. Pemajasan (figurative language, figures of chought) merupakan teknik pengungkapan bahasa, penggayabahasaan, yang maknanya tidak menunjuk pada makna harfiah kata-kata yang mendukungnya, melainkan pada makna yang ditambahkan atau makna yang tersirat (Nurgiyantoro, 2017:215). Novel merupakan salah satu bentuk dari karya sastra.Dalam novel, pengarang memaparkan realitas kehidupan manusia yang dibungkus dengan rapi dengan menggunakan bahasa. Novel London Love Story adalah salah satu dari beberapa novel karya Tisa TS yang sarat dengan diksi dan gaya bahasa. Novel London Love Story adalah novel terbaru selain dari Magic Hour.
\end{abstract}

Kata Kunci: Diksi, Gaya Bahasa

Abstract- Understanding diction or choice of words according to Keraf (2016: 24) is a choice of words or diction including understanding which words are used to convey an idea, how to form a grouping of the right words or use the right phrases, and which style is best used in a situation. Figurative language, figures of chought, is a technique of expressing language, language, whose meaning does not refer to the literal meaning of the words that support it, but rather to the added meaning or implied meaning (Nurgiyantoro, 2017: 215). Novel is one form of literary work. In the novel, the author describes the reality of human life wrapped neatly by using language. The London Love Story novel is one of several novels by Tisa TS that is loaded with diction and language style. The London Love Story novel is the latest novel aside from Magic Hour.

Keyword: Diction, Language Style

\section{PENDAHULUAN}

Istilah sastra dipakai untuk menyebut gejala budaya yang dapat dijumpai pada semua masyarakat meskipun secara sosial, ekonomi, dan keagamaan keberadaannya tidak merupakan keharusan.Hal ini berarti bahwa sastra merupakan gejala yang universal.Karya sastra sebagai bentuk dan hasil sebuah pekerjaan kreatif, pada hakikatnya adalah suatu media yang mendayagunakan bahasa untuk mengungkapkan tentang kehidupan manusia.Dalam menyampaikan imajinasi dalam bentuk karya sastra, pengarang menggunakan bahasa sebagai mediumnya.Sebagaimana yang dikemukakan (Esten dalam Samosir, 2013:3) karya sastra adalah karya seni yang berbicara tentang masalah hidup dan kehidupan, tentang manusia dan kemanusiaan yang menggunakan bahasa sebagai mediumnya. Sastra adalah seni 
bahasa, ungkapan spontan dari perasaan yang mendalam, ekspresi pikiran dalam bahasa (Sumardjo dan Saini K.M., 1988:2).

Bahasa merupakan sarana pengungkapan sastra.Jika sastra dikatakan ingin menyampaikan sesuatu, mendialogkan sesuatu, sesuatu tersebut hanya dapat dikomunikasikan lewat sarana bahasa.Bahasa dalam sastra pun mengemban fungsi utamanya, yaitu fungsi komunikatif.Hal ini seperti yang dijelaskan oleh Nurgiyantoro (2015:364) teks fiksi atau secara umum teks kesastraan, di samping sering disebut sebagai dunia dalam kemungkinan, juga dikatakan sebagai dunia dalam kata.Hal ini disebabkan "dunia" yang diciptakan, dibangun, ditawarkan, diabstraksikan, dan sekaligus ditafsirkan lewat kata-kata, lewat bahasa.

Diksi digunakan pengarang untuk memilih kata yang tepat untuk menciptakan makna tertentu dalam karya sastra.Dengan diksi itulah pengarang dapat menyusun kata demi kata dalam tulisannya.Diksi juga digunakan untuk menyampaikan suatu gagasan dari pengarang.Diksi adalah pemilihan kata.Ungkapan kata yang ditulis haruslah dipahami oleh pembaca dengan tepat.Untuk itulah, seorang penulis harus bisa memilih diksi yang tepat untuk tulisannya.Selain itu pilihan kata merupakan satu unsur yang sangat penting, baik dalam dunia karang mengarang maupun dalam dunia tutur setiap hari.

Dasar penggunaan bahasa dalam karya sastra bukan hanya sekedar paham, tetapi yang lebih penting adalah keberdayaan pilihan kata yang dapat mengusik dan meninggalkan kesan terhadap sensitivitas pembaca.Setiap kata yang dipilih oleh pengarang dapat diasosiasikan ke dalam berbagai pengertian. Misalnya kata ayu, bagus, apik, elok, memiliki denotasi atau arti yang sama, tetapi kesan kata-kata ini diarahkan pada sensitivitas yang berbeda. Setiap kata dan kalimat yang dipilih pada umumnya dilakukan atas kesadaran untuk menimbulkan efek keindahan.

Gaya bahasa juga digunakan oleh pengarang untuk memperindah tulisannya. Pengarang berusaha untuk menambahkan sebuah gaya bahasa di dalamnya. Penggunaan gaya bahasa atau bahasa kias dalam karya sastra dimaksudkan untuk memperoleh efek estetis atau keindahan sehingga pembaca akan lebih tertarik. Penggunaan bahasa kias dilakukan sebagai suatu cara untuk menimbulkan efek tertentu, sehingga penerima pesan lebih tertarik.

Proses penciptaan gaya bahasa dalam karya sastra jelas disadari oleh penulis atau pengarang. Itu dilakukan dalam rangka untuk memperoleh aspek keindahan tersebut secara maksimal. Pada dasarnya dalam karya sastra, gaya bahasa memegang peranan penting. Gaya bahasa dan penulisan merupakan salah satu unsur yang menarik dalam sebuah bacaan. Karena itu, pengarang memiliki gaya yang berbeda-beda dalam menuangkan setiap ide tulisannya. Setiap tulisan yang dihasilkan nantinya mempunyai gaya yang dipengaruhi oleh penulisnya, sehingga dapat dikatakan, 
watak seorang penulis sangat mempengaruhi sebuah karya yang dihasilkannya.

Novel merupakan salah satu bentuk dari karya sastra.Dalam novel, pengarang memaparkan realitas kehidupan manusia yang dibungkus dengan rapi dengan menggunakan bahasa. Oleh karena itu, penguasaan diksi dan gaya bahasa merupakan hal yang mutlak bagi penulis, sehingga karyanya dapat dinikmati dan gagasan-gagasan yang dimaksudkan penulis dapat tersampaikan dengan tepat kepada pembacanya. Selain itu, penulis dapat menghadirkan novel yang memiliki kekhasan dalam segi bahasa, sehingga membedakannya dengan bentuk sastra tulis lainnya.Keindahan dalam novel dibangun oleh pengarang melalui seni kata.Seni kata atau seni bahasa berupa katakata yang indah terwujud dari ekspresi jiwa.

Untuk dapat menikmati novel yang memiliki nilai estetika, salah satunya adalah melalui kajian stilistika.Kajian stilistika dimaksudkan untuk menjelaskan fungsi keindahan penggunaan bentuk kebahasaan tertentu mulai dari aspek bunyi, leksikal, struktur, bahasa figuratif, sarana retorika, sampai grafologi (Nurgiyantoro, 2017:76).Selain itu, dijelaskan juga bahwa penelitian estetika berdasarkan asumsi bahwa bahasa sastra mempunyai tugas mulia.Bahasa memiliki pesan keindahan dan sekaligus membawa makna.Tanpa keindahan bahasa karya sastra menjadi hambar (Endraswara, 2003:72).Keindahan karya sastra, hampir sebagian besar dipengaruhi oleh kemampuan penulis memainkan bahasa. Dengan demikian, dapat dikatakan bahwa stilistika adalah penggunaan gaya bahasa secara khusus dalam karya sastra yang menimbulkan nilai keindahan sehingga sastra tidak menjadi hambar.

Dalam penelitian ini peneliti akan membahas mengenai diksi dan gaya bahasa dalam novel London Love Story karya Tisa TS. Pilihan kata atau yang biasa disebut diksi merupakan satu unsur yang sangat penting, kata yang tepat akan membantu seseorang mengungkapkan dengan tepat apa yang akan disampaikannya, baik lisan maupun tulis. Untuk itulah, seorang penulis harus bisa memilih diksi yang tepat untuk tulisannya. Selain diksi, pengarang sebuah novel yang baik adalah pengarang yang dapat memainkan kata-kata, ia dapat menciptakan berbagai gaya bahasa dalam penceritaan dari rentetan alur dan peristiwaperistiwa yang terjadi dalam novel. Pada hakikatnya gaya bahasa adalah cara khas penulis dalam mengungkapkan imajinasinya melalui bahasa tulis. Oleh karena itu, menurut peneliti hal ini sangatlah penting untuk diteliti agar dapat memberikan pemahaman kepada pembaca tentang makna yang terkandung dalam diksi dan gaya bahasa dalam novelLondon Love Story karya Tisa TS.

Novel London Love Story adalah salah satu dari beberapa novel karya Tisa TS yang sarat dengan diksi dan gaya bahasa. Novel London Love Story adalah novel terbaru selain dari Magic Hour.Seperti halnya novel Magic Hour dalam novel London Love Story kekuatan 
bahasa yang ditampilkan Tisa TS menjadi daya tarik bagi pembaca untuk mengikuti jalan ceritanya. Ketangkasan memilih dan mengolah kata yang dilakukan oleh Tisa TS mampu menghasilkan nuansa estetis.. Novel-novel Tisa TS selalu mengangkat tema tentang kehidupan percintaan di kalangan remaja yang disajikan dengan gaya bahasa yang mampu menghidupkan suasana cerita dan mudah dipahami pembaca.

Penggunaan gaya bahasa yang bervariasi juga mewarnai cerita dalam novel London Love Story yang menimbulkan kesan imajinatif bagi pembaca. Kisah dalam novel London Love Story telah diangkat ke layar lebar dan telah berhasil menarik tak kurang dari satu juta penonton.Cerita dalam novel ini sangat unik dan nyentrik. Hal inilah yang menjadi alasan dipilihnya novel London Love Story ditelitidari segi stilistika karena setelah membaca novel tersebut, banyak ditemukan keanekaragaman diksi dan gaya bahasayang digunakan Tisa TS dalam novelnya, sehingga sangat perlu dan menarik untuk dianalisis.

\section{METODE PENELITIAN}

Metode adalah cara yang dipergunakan seorang peneliti di dalam usaha memecahkan masalah yang diteliti (Siswantoro, 2008:55-56). Oleh sebab itu, penelitian merupakan kegiatan ilmiah, metode harus sistematis atau prosedural.Sistematis maksudnya seorang peneliti harus bekerja secara teratur di dalam upaya memecahkan masalah.
Metode penelitian pada dasarnya merupakan cara ilmiah untuk mendapatkan data dengan tujuan dan kegunaan tertentu (Sugiyono, 2010:2). Penelitian ini merupakan penelitian deskriptif kualitatif.Penelitian kualitatif adalah metode penelitian yang berlandaskan pada filsafat postpositivisme, digunakan untuk meneliti pada kondisi objek yang alamiah.

\section{PEMBAHASAN}

Berdasarkan hasil temuan di atas, diketahui bahwa dalam novel London Love Storykarya Tisa TS terdapat beragam diksi dan gaya bahasa yang digunakan. Diksi yang digunakan oleh pengarang antara lain kata konotasi, kata asing, idiom, dan kata sapaan.Diksi adalah penentuan kata-kata seorang pengarang untuk mengungkapkan gagasannya.Selain itu, diksi dapat juga diartikan sebagai pilihan kata-kata yang dilakukan oleh pengarang dalam karyanya guna menciptakan efek makna tertentu (Al-Ma'ruf, 2012:49).Seorang penulis harus berusaha secermat mungkin memilih kata-katanya untuk mencapai maksud tersebut.

Dalam novel London Love Story karya Tisa diketahui bahwa diksi yang paling dominan digunakan adalah bahasa asing.Kata asing ialah unsur-unsur yang berasal dari bahasa asing yang masih dipertahankan bentuk aslinya karena belum menyatu dengan bahasa aslinya (Keraf, 2008:89-108). Pemanfaatan kata asing dalam novel London Love Story karya Tisa TS dapat dilihat pada kata, frasa, dan kalimat yang 
digunakan dalam kalimat bahasa Indonmesia. Tisa TS sebagai seorang penulis skenario dan juga sebagai jurnalis tentunya telah menguasai banyak kosa kata asing dalam setiap tulisan yang dibuatnya.Hal-hal yang berhubungan dengan penulisan sudah menjadi makanan setiap hari terutama kata asing. Penggunaan kata asing dalam novel London Love Story dalam bentuk kata seperti disconnect, mood, shut up, laundry, move on, promise, dinner, wait, happy, menghiasi cerita dalam novel London Love Story. Data-data ini menunjukkan bahwa Tisa TS kaya akan perbendaharaan kosakata bahasa Inggris. Selanjutnya, data-data yang menggunakan frasa bahasa Inggris dalam deskripsi cerita diantaranya sebagai berikut.

(1) Beberapa orang telah terlihat getting high termasukneneknya Bayu yang sudah mendengkurdi atas sofa (Sari, 2015:24).

(2) Di London pun, Caramel juga mengambil part time jobdi sebuah kafe pizza di tengah kota, sebagai usaha untuk meringankan biaya hidup yang tinggi

(Sari, 2015:8).

Data di atas menunjukkan bahwa pemanfaatan frasa bahasa Inggris dapat ditemukan dalam sebuah kalimat. Frasa bahasa Inggris pada data (1)getting high yang artinya mabuk atau teller, data (2) part time job yang artinya bekerja paruh waktu menunjukkan bahwa Tisa Ts sang penulis mempunyai wawasan pengetahuan yang hebat. Selain itu, penggunaan frasa bahasa Inggris tersebut membuat deskripsi cerita tidak terlihat monoton. Selain kata dan frasa bahasa Inggris juga terdapat pemakaian kalimat dalam bahasa Inggris untuk mendeskripsikan cerita. Seperti pada data berikut.

(3) "Hey, I am back! Wait .... Adelle mengendus sesuatu. "Wow, smells good. Kamu lagi masak?” (Sari, 2015:124).

(4) “There's no hope. You should sign this. I'm sorry, but there's no choice (Sari, 2015:180).

Pemilihan dan pemakaian kalimat bahasa Inggris pada data-data di atas menunjukkan bahwa Tisa TS sangat memahami dan menguasai leksikon bahasa Inggris.Selain itu juga pemakaian kosa kata bahasa Inggris memperlihatkan intelektualitas pengarang tentang wawasan dan pengetahuan yang luas mengenai leksikon bahasa Inggris, serta memperlihatkan kepiawaian pengarang dalam menggunakannya dalam kalimat.

Berdasarkan analisis mengenai pemilihan dan pemakaian kosakata bahasa Inggris dalam deskripsi cerita terdapat leksikon bahasa Inggris yang berupa kata sebanyak 18 data, frasa 8 data dan berupa kalimat 19 data.Hal ini secara tidak langsung penggunaan leksikon bahasa Inggris dalam deksripsi cerita dipengaruhi oleh latar belakang penulis. Tisa TS dikenal sebagai penulis skenario dan jurnalis 
tentunya menguasai banyak kosakata dalam bahasa asing khususnya bahasa Inggris.Selain itu, dilatarbelakangi juga oleh latar tempat novel London Love Story di luar negeri tepatnya di London.Hal ini tentu saja Tisa TS dengan mudah memakai leksikon bahasa Inggris dalam deskripsi cerita yang dibuatnya. Dengan penggunaan leksikon bahasa Inggris cerita yang dibuat lebih menarik dan juga dapat membuat pembaca semakin terpesona dengan kepiawaian Tisa TS dalam mengkombinasikan bahasa Inggris dengan bahasa Indonesia dalam deskripsi cerita dengan tidak mengurangi maknanya. Selain kata asing, pemakaian kata konotasi, kata sapaan, dan idiom dalam novel London Love Story karya Tisa TS membuat deskripsi cerita semakin bermakna, menarik dan memikat pembaca.

Dari hasil penelitian novel London Love Story karya Tisa TS, peneliti menemukan beberapa variasi gaya bahasa antara lain gaya bahasa personifikasi, hiperbola, simile, repetisi dan sarkasme. Style atau gaya bahasa dapat diartikan sebagai cara mengungkapkan pikiran melalui bahasa secara khas yang memperlihatkan jiwa dan kepribadian penulis pemakai bahasa (Keraf, 2006:13). Gaya bahasa dalam karya sastra merupakan suatu alat untuk melakukan atau menggambarkan, menegaskan inspirasi atau ide dalam bentuk gaya yang indah.

Berdasarkan hasil penelitian di atas, gaya bahasa yang dominan ditemukan dalam novel London Love Story karya Tisa TS adalah gaya bahasa repetisi. Repetisi merupakan perulangan bunyi, suku kata, kata, bagian kalimat yang dianggap penting untuk memberi tekanan dalam sebuah konteks yang sesuai (Sumarlam, 2003:35).Gaya bahasa repetisi hadir dalam novel London Love Story memberikan berbagai efek estetika dalam peneceritaan. Misalnya sebagai efek keindahan dalam jalinan cerita, keterpaduan pengulangan kata-kata yang indah dan berirama juga akan menciptakan suasana hati yang menyenangkan ketika membaca sebuah karya. Selain dari itu, repetisi juga menciptakan efek penegasan, penekanan sekaligus penguatan pada isi cerita. Pemakaian dan pemanfaatan repetisi sekaligus sebagai cara untuk menarik perhatian pembaca ke dalam detail cerita. Dengan demikian, repetisi memberikan penguatan pada isi cerita. Pada repetisi setiap detail cerita yang memang dianggap penting maka akan diulang beberapa kali. Hal ini bertujuan agar pembaca dapat dengan mudah menangkap pesan yang ingin ditekankan dalam cerita tersebut. Berikut gaya bahasa repetisi yang peneliti temukan dalam novel London Love Story karya Tisa TS.

(5) "Maafin aku, maafin aku! Tapi kamu nggak tahu, bagaimana lebih dari setahun aku ngelewatin hari-hari aku ..." Air mata Caramel semakin menetes membasahi wajah mantannya. (Sari, 2015:173).

(6) "Kamu ingetkan apa yang kamu tulis buatku? Kamu ingetkan kamu pernah berjanji sama aku (Sari, 2015:182). 
Pada data (5) terdapat pengulangan frasa maafin aku, pada data (6) terdapat pengulangan frasa kamu inget kan. Pengulangan kata dalam kalimat tersebu berfungsi sebagai penegasan deskripsi cerita agar makna yang ingin disampaikan penulis dapat ditangkap lebih jelas oleh pembaca..Selain itu pengulangan kata berfungsi juga untuk menekankan kata tersebut dalam konteks tuturan. Dalam novel London Love Story, Tisa TS membuat penekanan-penekanan khususnya pada kata yang diulang adalah untuk memperindah deksripsi cerita yang dibuat dan menonjolkan makna yang akan disampaikan kepada pembaca.

Gaya bahasa dominan lainnya dalam novel London Love Story karya Tisa TS adalah gaya bahasa simile. Gaya bahasa simile adalah gaya bahasa yang berusaha membandingkan sesuatu secara eksplisit dengan mennggunakan kata-kata pembanding seperti, bagai, bak, laksana dan ibarat. Tujuan dari gaya bahasa simile yang digunakan pengarang adalah untuk menghidupkan sebuah tuturan. Tuturan yang awalnya sulit untuk dipahami akan menjadi lebih mudah dengan dimanfaatkannya gaya bahasa simile seperti pada kalimat berikut.

Ia adalah sedikit dari anak Indonesia di London yang sanggup menikmati hidup mewah dan glamour bak selebritis (Sari, 2015:20).
Pemakaian gaya bahasa simile dalam kalimat tersebut ditandai dengan pemakaian kata bak. Tujuan pemakaian gaya bahasa simile adalah untuk menghidupkan tuturan agar lebih hidup, lebih indah, dan lebih komunikatif. Hal ini tentunya akan berbeda jika pengarang menulis dengan kalimat: Hidupnya mewah dan glamour maka nilai rasa yang ditimbulkan dari kalimat tersebut kurang estetis karena cenderung menggunakan kalimat yang bermakna denotatif. Meskipun keduanya sama-sama menggambarkan hidup mewah dan glamour.Jika dibandingkan dengan kalimat hidupnya mewah dan glamour bak selebritis maka pembaca tidak hanya dapat menangkap maksud bahwa hidupnya memang benar-benar mewah namun juga dapat menangkap sebuah citraan atau bayangan yang ditimbulkan dari perbandingan tersebut.

Variasi gaya bahasa lain yang dimanfaatkan oleh pengarang dalam novel London Love Story adalah gaya bahasa personifikasi. Gaya bahasa personifikasi dalam novel ini mampu menciptakan efek estetis dengan menggunakan ragam kalimat yang lebih indah dan bervariatif sehingga cerita yang disajikan lebih menarik dan tidak monoton.Misalnya ketika menggambarkan angin kencang yang datang dari arah laut menyapu dermaga, suara air di shower terkesan memprotes dirinya dan sebagainya.Gaya bahasa personifikasi juga mampu membantu menghidupkan imajinasi pembaca. Pembaca akan mudah membayangkan atau menghayalkan 
benda-benda ketika dikaitkan dengan hal-hal yang berhubungan dengan kehidupan manusia seperti diberikan sifat kemanusiaan. Seperti yang dikemukakan oleh Pradopo (2010:74) bahwa sebuah personifikasi mampu membuat hidup sebuah lukisan, memberikan kejelasan, serta mampu memberikan gambaran bayangan angan yang konkret.

Selanjutnya gaya bahasa hiperbola juga dimanfaatkan oleh pengarang dalam novel London Love Story. Misalnya ketika menggambarkan suara geledek yang kuat, pilihan kata yang digunakan adalah membelah. Pilihan kata yang digunakan dalam gaya bahasa hiperbola bertujuan untuk melebih-lebihkan sesuatu atau suara yang didengar. Selain itu, penggunaan gaya bahasa hiperbola juga untuk membantu pembaca dalam menangkap imajinasi yang terkandung dalam cerita, sehingga cerita yang disajikan lebih hidup karena efek penggambaran dan citraan yang ditampilkan terlihat lebih nyata dengan gaya yang melebihlebihkan sebuah kenyataan. Misalnya ketika pengarang menggambarkan bunyi geledek, pengarang memanfaatkan gaya bahasa hiperbola dengan mengatakan bunyi geledek membelah bumi .

Gaya bahasa yang juga menghidupkan cerita dalam novel London Love Story adalah Gaya bahasa Sarkasme.Sarkasme merupakan acuan yang lebih kasar dari ironi dan sinisme.Gaya ini selalu menyakitkan dan kurang enak didengar (Keraf, 2006:143).Sarkasme adalah sindiran langsung dan kasar.Dalam novel London Love Story ditemukan kalimat seperti berikut.

Gua langsung lupain si brengsek yang sudah bikin gue mau loncat kemarin," oceh Adelle panjang lebar (Sari, 2015:88).

Kata brengsek pada kutipan di atas merupakan gaya bahasa sarkasme. Kata brengsek merujuk pada penyebutan yang ditujukan kepada seseorang yang nilai rasanya lebih kasar jika disbanding gaya bahasa ironi dan gaya bahasa sinisme. Kata ini sangat menyakitkan bagi orang yang disebutnya. Pemanfaatan gaya bahasa sarkasme oleh pengarang bertujuan untuk mengajak pembaca berimajinasi membayangkan keadaan yang dialami tokoh si pacar yang dikatakan kurang ajar. Pembaca seolah-olah ikut larut dan merasakan seperti yang digambarkan dalam cerita.

Novel London Love Story ditulis dengan gaya khas Tisa TS dengan menggunakan bahasa sehari-hari sehingga mudah dicerna oleh pembacanya dan dengan cepat ditangkap pembacanya. Diselipi dengan bahasa gaul yang hits pada masa kini, membuat novel ini semakin keren. Penggunaan diksi yang bervariasi menjadikan deskripsi cerita semakin menarik, memikat, dan menambah nilai estetis dalam deskripsi ceritanya.Selain itu untuk menambah daya tarik tersendiri bagi pembaca.Semua ini 
tentunya menjadi style dan ciri khusus tersendiri bagi Tisa TS dalam karya-karyanya.

Pemanfaatan gaya bahasa yang beragam yang digunakan pengarang dalam novel London Love Story oleh Tisa TS memiliki makna dan fungsi tersendiri dalam mewujudkan keberhasilan karyanya. Manfaat gaya bahasa bagi pembaca sangatlah beragam diantaranya untuk menciptakan efek-efek tertentu dalam hal ini efek estetis dalam kalimat, efek penegasan pada bagian tertentu dalam cerita yang memang dianggap penting, menunjukkan kekhasan atau mengikuti trend tertentu pada sebuah tulisan, memberikan penguatan, mengkonkretkan hal-hal yang bersifat abstrak, menciptakan gambaran atau citraan yang nyata dengan cara melebihlebihkan cerita, serta membantu daya imajinasi pembaca. Meskipun masing-masing gaya bahasa memiliki makna dan fungsi yang berbeda, tetapi memiliki tujuan yang sama dalam upaya menghidupkan cerita. Begitu juga dengan pengarang.Setiap pengarang mempunyai style tersendiri dalam menyampaikan karyanya. Latar belakang pengarang yang berbeda tentunya menjadikan karyanya pun menjadi berbeda dengan pengarang lain. Hal ini tentunya akan menjadi ciri khas gaya penulisannya.

\section{SIMPULAN}

Berdasarkan hasil analisis stilistika novel London Love Story karya Tisa TS dan pembahasan yang dilakukan oleh peneliti maka, dapat disimpulkan bahwa novel London Love
Story karya Tisa TS setelah dikaji dengan pendekatan stilistika peneliti menemukan beberapa hal yaitu: (1) kemampuan pengarang dalam menyampaikan ceritanya dengan menggunakan diksi atau pilihan kata seperti konotasi, kata sapaan, kata asing khususnya bahasa Inggris, dan idiom, (2) kemampuan pengarang dalam menyampaikan ceritanya dengan menggunakan gaya bahasa seperti gaya bahasa personifikasi, gaya bahasa hiperbola, gaya bahasa simile, gaya bahasa repetisi, dan gaya bahasa sarkasme.

Diksi yang digunakan oleh pengarang dalam novel London Love Story pada umumnya berfungsi untuk menjadikan deskripsi cerita semakin menarik, memikat, dan menambah nilai estetis.Dari data diksi yang dilakukan peneliti diketahui bahwa diksi yang dominan digunakan pengarang dalam novel London Love Story adalah diksi kata asing khususnya bahasa Inggris.Diksi kata asing yang digunakan oleh penulis sangat sesuai dengan judul novel itu sendiri yang menggunakan bahasa asing.Selain itu latar tempat di luar negeri (London) juga mendukung banyaknya penggunaan kosakata bahasa asing dalam novel tersebut. Penggunaan diksi asing yang digunakan pengarang dapat membuat pembaca semakin terpesona dengan kepiawaian pengarang dalam mengombinasikan bahasa Inggris dengan bahasa Indonesia dalam deskripsi cerita tanpa harus mengurangi maknanya. Selain itu pemanfaatan bahasa asing menjadikan deskripsi cerita tidak monoton. 
Variasi gaya bahasa yang digunakan dalam novel London Love Story antara lain (1) gaya bahasa personifikasi, (2) gaya bahasa hiperbola, (3) gaya bahasa simile, (4) gaya bahasa repetisi, (5) gaya bahasa sarkasme. Masing-masing gaya bahasa memiliki makna dan fungsi tersendiri dalam mendukung keberhasilan karyanya. Dari beberapa gaya bahasa yang digunakan pengarang dalam novel London Love Story gaya bahasa yang dominan dipakai pengarang adalah gaya bahasa repetisi. Repetisi memberikan penguatan pada isi cerita. Pada repetisi setiap detail cerita yang memang dianggap penting maka akan diulang beberapa kali. Hal ini bertujuan agar pembaca dapat dengan mudah menangkap pesan yang ingin ditekankan dalam cerita tersebut.

Meskipun masing-masing gaya bahasa memiliki makna dan fungsi yang berbeda, namun pada intinya tujuan yang ingin dicapai sama yakni turut menyumbangkan kebermanfaatannya dalam menghidupkan cerita. Pada umumnya gaya bahasa yang digunakan pengarang dalam novel London Love Story adalah untuk menciptakan efek estetis serta membantu daya imajinasi pembaca.

\section{DAFTAR PUSTAKA}

Al-Ma'ruf., Ali Imron. 2009. Stilistika: Teori, Metode, dan Aplikasi Pengkajian Estetika Bahasa. Solo: Cakra Books.

Al-Ma'ruf, Ali Imron. 2012. Stilistika: Teori, Metode, dan Aplikasi Pengkajian Estetika Bahasa. Solo: Cakra Books.
Aminudin.1990. Pengembangan Penelitian Kualitatif dalam Bidang Bahasa dan Sastra. Malang: Yayasan Asah Asih bAsuh.

Aminudin, 1995. "Stilistika :Pengantar Memahami Bahasa dalam Karya Sastra. Semarang: IKIP Semarang Press.

Aminudin. 2014. Pengantar Apresiasi Karya Sastra. Bandung: Sinar Baru Algensindo offset.

Arikunto, Suharsimi. 1992..Prosedur Penelitian Suatu Pendekatan Praktik. Jakarta: Rineka Cipta.

Arikunto, Suharsimi. 1998. Prosedur Penelitian Suatu Pendekatan. Jakarta: Rineka Cipta.

Arikunto, Suharsimi, 2010. Prosedur Penelitian Suatu Pendekatan. Jakarta: Rineka Cipta.

Endraswara, Sowardi. 2003. Metodologi Penelitian Satra. Jakarta: PT Buku Seru.

Endraswara, Sowardi. 2008. Metodologi Penelitian Sastra. Jakarta: PT Buku Seru.

Esten, Mursal. 2013. Kesusastraan Pengantar Teori dan Sejarah. Bandung: Angkasa.

Jabrohim. 2017. Teori Penelitian Sastra. Yogyakarta: Pustaka Pelajar.

Juwati. 2015. Diksi dan Gaya Bahasa Puisipuisi Sutardji Calzoum Bachri (Sebuah Kajian Stilistika). (Jurnal).STKIP Lubuk Linggau.

Kemendiknas. 2011. Panduan Pelaksanaan Pendidikan Karakter. Jakarta: Badan Penelitian dan Pengembangan, Pusat Kurikulum dan Perbukuan. 
Keraf, Gorys. 2006. Diksi dan Gaya Bahasa. Jakarta: PT Gramedia Pustaka Utama.

Keraf, Gorys. 2008. Penelitian Gaya Bahasa dalam Karangan. Jakarta: PT Gramedia.

Keraf, Gorys. 2009. Diksi dan Gaya Bahasa. Jakarta:PT Pustaka Utama..

Keraf, Gorys . 2016. Diksi dan Gaya Bahasa. Jakarta: PT Gramedia Pustaka Utama..

Kosasih, E. 2003.Apresiasi Sastra Indonesia. Jakarta: Nobel Edu Media.

Miles, M.B dan Michael Huberman.1992.Analisis Data Kualitatif. Jakarta: Universitas Indonesia Press.

Marfuah Unsayaini, dkk. Kajian Stilistika Novel Assalamualaikum Beijing Karya Asma Nadia dan Relevansinya sebagai Materi Ajar Bahasa Indonesia di Kelas XII SMA. Jurnal Penelitian Bahasa, Sastra Indonesia dan Pengajarannya Volume 4 Nomor 1, April 2016, ISSN12302-6405.

Moelong, Lexy. 2011. Metode Penelitian Kualitatif. Bandung: Remaja Rosdakarya.

Munir, Syaiful.dkk. 2013. Diksi dan Majas dalam Kumpulan Puisi Nyanyian Dalam Kelam karya Sutikno W.S. Kajian Stilistika (Jurnal). Fakultas Bahasa dan Seni.Universitas Negeri Semarang.

Mushaitir. 2012. Kajian Stilistika Cerpen Aku Datang Bersama Lautan Karya Firman Venayaksa.(Jurnal).Program Studi Pendidikan Bahasa dan Sastra Indonesia.Fakultas Keguruan dan Ilmu
Pendidikan. Universitas Nahdatul Wathan Mataram.

Mustakim.1994. Membina Kemampuan Berbahasa Panduan ke Arah Kemahiran Berbahasa. Jakarta: PT. Gramedia Pustaka Umum.

Ningrum, Ratih Septiyani. 2015. Diksi dan Gaya Wacana Pada Wacana Novel Pasir Pun Enggan Berbisisk Karya Taufiqurrahman Al-Azizy Kajian Stilistika Sebagai Bahan Ajar Sastra di SMA (Jurnal) Program Studi Bahasa dan Sastra Indonesia Fakultas Keguruan dan Ilmu Pendidikan Universitas Muhammadiyah Surakarta.

Nurgiyantoro.Burhan. 2010.Teori Pengkajian Fiksi. Yogyakarta: Gajah Mada University Press.

Nurgiyantoro, Burhan. 2015. Teori Pengkajian Sastra. Yogyakarta: Gadjah Mada University Press.

Nurgiyantoro, Burhan. 2017. Stilistika. Yogyakarta: Gadjah Mada University Press.

Pradopo, Djoko Rachmat. 1993. Pengkajian Puisi. Yogyakarta: Gadjah Mada University.

Pradopo, Djoko Rachmat. 2010. Pengkajian Puisi. Yogyakarta: Gadjah Mada University.

Ratna, Nyoman Kutha. 2007. Stilistika Kajian Puitika Bahasa, Sastra, dan Budaya. Yogyakarta: Pustaka Pelajar.

Ratna, Nyoman Kutha. 2014. Stilistika Kajian Puitika Bahasa, Sastra, dan Budaya. Yogyakarta: Pustaka Pelajar. 
Ratna, Nyoman Kutha. 2017. Stilistika Kajian Puitika Bahasa, Sastra, dan Budaya. Yogyakarta: Pustaka Pelajar.

Samosir, Tiorida. 2013. Apresiasi Puisi. Jakarta: Yrama Widya.

Sari, Tisa Tisi. 2015. London Love Story. Jakarta: PT Cahaya Duabelas Semesta

Siswantoro, 2008.Metode Penelitian Sastra. Yogyakarta: Pustaka Pelajar.

Siswantoro. 2010. Metode Penelitian Sastra.. Yogyakarta: Pustaka Pelajar.

Stanton, Robert. 2012. Teori Fiksi. Yogyakarta: Pustaka Pelajar Offset.

Sudjiman, Panuti. 1993. Bunga Rampai Stilistik. Jakarta: Pustaka Utama Grafiti.

Subrayogo. 2001. Metodologi Penelitian Sosial-Agama. Bandung:Remaja Rosda Karya.

Sugiyono. 2006. Metode Penelitian Kuantitatif, Kualitatif dan $R \& d$. Bandung: Alfabeta.

Sugiyono.. 2010. Metode Penelitian Kuantitatif , Kualitatif dan $R \& D$. Bandung: Alfabeta.

Sugiyono. 2014. Metode Penelitian Kuantitatif - Kualitatif, dan $R \& D$. Bandung:
Alfabeta.

Sumardjo, Jakob dan Saini K.M. 1988.Apresiasi Kesusastraan. Jakarta: Gramedia.

Sumarlan, 2003.Teori dan Praktik Analisis Wacana. Surakarta: Pustaka Cakra.

Tarigan, Henry Guntur. 1986. Pengajaran Gaya Bahasa. Bandung: Angkasa.

Tarigan, Henry Guntur. 2013. Pengajaran Gaya Bahasa. Bandung: Angkasa.

Universitas PGRI Palembang. 2019. Pedoman Penulisan Tesis. Palembang: Program Pascasarjana Universitas PGRI Palembang.

Waluyo, J. Herman. 2002. Pengkajian Sastra Rekaan. Salatiga: Widya Sari Press.

Wardani, Nugrahaeni Eko. 2009. Makna Totalitas dalam Karya Sastra. Surakarta: LPP UNS dan UNS Press.

Zuchdi, Darmiyati. 1993. Panduan Penelitian Analisis Konten. Yogyakarta: Lembaga Penelitian IKIP Yogyakarta 
